\title{
Spatial variation of aerosol properties over Europe derived from satellite observations and comparison with model calculations
}

\author{
C. Robles González ${ }^{1}$, M. Schaap ${ }^{2,3}$, G. de Leeuw ${ }^{1}$, P. J. H. Builtjes ${ }^{2,3}$, and M. van Loon $^{2}$ \\ ${ }^{1}$ TNO, Physics and Electronics Laboratory, PO-BOX 96864, NL-2509 JG The Hague, The Netherlands \\ ${ }^{2}$ TNO, Institute of Environmental Science, Energy Research and Process Innovation, PO-Box 342, NL-7300 AH, Apeldoorn, \\ The Netherlands \\ ${ }^{3}$ Utrecht University, Institute of Marine and Atmospheric Sciences, PO-Box 80005, NL-3508 TA, Utrecht, The Netherlands
}

Received: 5 November 2002 - Published in Atmos. Chem. Phys. Discuss.: 29 January 2003

Revised: 29 April 2003 - Accepted: 7 May 2003 - Published: 20 May 2003

\begin{abstract}
Aerosol optical depths (AOD) and Angström coefficients over Europe were retrieved using data from the ATSR-2 radiometer on board the ESA satellite ERS-2, for August 1997. Taking advantage of the nadir and forward view of the ATSR-2, the dual view algorithm was used over land to eliminate the influence of the surface reflection. Over sea the AOD was retrieved using only the forward observations. Retrieved aerosol optical properties are in good agreement with those from ground-based sunphotometers. The AOD and Angström coefficients together yield information on the column integrated effective aerosol distribution.

Observed regional variations of the AOD and Angström coefficient are related to anthropogenic emissions of aerosol precursors such as $\mathrm{SO}_{2}$ and $\mathrm{NO}_{\mathrm{x}}$ in the major European industrial and urban areas, and their subsequent transformation into the aerosol phase. The influence of anthropogenic aerosols such as ammonium sulphate and ammonium nitrate on the total AOD is estimated using a regional chemistry transport model. Sulphate is estimated to contribute from $15 \%$ in very clean areas to $70 \%$ in polluted areas, the contribution of nitrate is between 5\% and 25\% over most of Europe. This paper shows the great importance of nitrate in summer over The Netherlands.
\end{abstract}

\section{Introduction}

Satellite remote sensing can be a cost-effective method to monitor the highly variable aerosol fields on regional to global scales. Radiative forcing of aerosol can be estimated with an accuracy of $1 \mathrm{Wm}^{-2}$ for aerosol optical depths higher than 0.1 (King et al., 1999). Until recently it was thought that the retrieval of aerosol properties from satellite data was only possible over dark surfaces, such as the ocean. However,

Correspondence to: C. Robles González

(robles-gonzalez@fel.tno.nl) novel satellite sensors allow for the retrieval of aerosol properties over land (Kaufman et al., 1997; Veefkind et al., 1998, Martonchik and Diner, 1992). For example, the Along Track Scanning Radiometer (ATSR-2) on board the European Remote Sensing satellite (ERS-2) was successfully used to retrieve aerosol properties over water (Veefkind and De Leeuw, 1998), and taking advantage of the dual view and the multiple wave bands, also over land (Veefkind et al., 1998; Robles González et al., 2000).

Both aerosol optical depth (AOD) and the Angström coefficient can be derived from satellite data, as column integrated properties. Together, these two parameters can be used to estimate the column integrated effective particle size distribution. The AOD provides information on the total concentration in a certain size range; the Angström coefficient gives an indication on the shape of the particle size distribution. Small values of the Angström coefficient indicate the dominance of large particles, such as sea salt or dust and large Angström coefficients are usually obtained when small particles such as sulphate, nitrate and biomass burning particles dominate. An analysis of simultaneous measurements of aerosol composition and aerosol optical depth shows that relations can be derived between mass concentrations of several aerosol components and Angström coefficients (Kusmierczyk-Michulec et al., 2002).

To further explore the possibilities of satellite remote sensing of aerosol, the results can be interpreted using closure measurements (Veefkind et al., 1998, 1999; Durkee et al., 2000), or they can be compared with results from chemistry transport models (e.g. Tegen et al., 1997; Jeuken et al., 2001). Tegen et al. used a global transport model to calculate the spatial distributions of various aerosol species. From comparison of their model results with AVHRR data, i.e. over the oceans, information on the contributions of each aerosol type to the total AOD was derived.

Jeuken et al. (2001) used results from Robles González et al. (2000) of the mean AOD over Europe for August 1997, 
to validate the sulphate and nitrate aerosol distributions calculated with the global transport model TM-3, with a spatial resolution of $2.5^{\circ} \times 2.5^{\circ}$. To this end, the retrieved AOD data had to be re-sampled to this grid size, thus loosing much of the spatial resolution in the original data provided by the ATSR-2 (pixel size $1 \times 1 \mathrm{~km}^{2}$ ).

The present study is aimed at demonstrating the complementary use of aerosol observations from satellites and the results of regional-scale chemistry transport models. The focus of the study is Europe. The large variation in both the AOD and the Angström coefficient, as well as their spatial gradients around industrialised areas indicate the influence of local emissions of primary aerosols and/or precursor gases (Robles González et al., 2000). The precursor gases lead to the formation of secondary aerosols which also contributes to the variation of the total AOD. This is further investigated by using a regional scale chemistry transport model extended with an aerosol module for ammonium sulphate and ammonium nitrate.

The satellite data have a minimum pixel size of $1 \times 1 \mathrm{~km}^{2}$. In this study use is made of averaged values of $10 \times 10 \mathrm{~km}^{2}$. The chemistry transport model LOTOS used in this study has at the moment a finest resolution over Europe of $0.25 \times 0.5$ latitude-longitude, i.e. a factor 50 finer than current global models, sufficient to analyse spatial variations of aerosol properties over Europe.

\section{Aerosol properties from satellite data}

\subsection{Algorithms description}

In order to retrieve the aerosol properties over Europe from ATSR-2 data, the dual view (DV) algorithm developed by Veefkind et al. (1998) has been used over land and the single view (SV) algorithm developed by Veefkind and De Leeuw (1998) has been used over water. Both algorithms are based on two assumptions. First, the top of atmosphere (TOA) reflectance due to an external mixture of two different aerosol types can be approximated as the weighted average of the reflectance of the individual aerosol types (Wang and Gordon, 1994). Second, the TOA reflectance is approximated as a linear function of the AOD (Durkee et al., 1986).

The DV algorithm also assumes that the ratio of the surface reflectance for the nadir and forward view of the ATSR2 is independent of the wavelength (Flowerdew and Haigh, 1995). This assumption has been recently reviewed by North (2002).

Over water the dual view algorithm may yield erroneous results (Veefkind et al., 1999). In contrast to the situation over land, where the surface reflectances in both the forward and the nadir view are one order of magnitude larger than the aerosol reflectance, over turbid coastal waters the surface reflectance in the nadir view is similar to the aerosol reflectance. This renders the distinction between aerosol and surface effects difficult. Therefore, over water the single view algorithm, which assumes a dark surface (Veefkind and De Leeuw, 1998), was applied to data from the forward view.

Both algorithms include multiple scattering and the bidirectional reflectance of the surface. They are based on comparison of computed TOA reflectances with the ATSR-2 data. Hence information is needed on the aerosol contribution to the TOA reflectance. This information is obtained from aerosol models describing the physical and chemical properties of the aerosol expected to be present in the study area. These aerosol models are used to calculate look up tables (LUTs) containing the calculated TOA reflection. The reflectance of the modeled aerosols is compared with the TOA reflectance measured by the satellite to determine which aerosol type best describes the spectral variation. Sea salt and continental (non-absorbing) aerosols are included in the algorithms. To compute the scattering matrix of the aerosols a Mie scattering code by De Rooij and van der Stap (1984) was used. The LUTs are computed using the discrete ordinate method DISORT (Stammes et al., 1988).

\subsection{Aerosol optical depth}

Figure 1 shows the mean AOD over Europe for August 1997 at $0.555 \mu \mathrm{m}$, obtained as the average of all available ATSR-2 data. With one overpass every three days, i.e. a maximum of 11 overpasses during August 1997, and further reduction of the available data due to contamination by clouds or sunglint, these averages represent all valid data points, which are snapshots at the time of the ATSR-2 overpass (around 11:00 a.m.). The original AOD values, with a resolution of $1 \times 1 \mathrm{~km}^{2}$, were averaged on a $10 \times 10 \mathrm{~km}^{2}$ grid as described in Robles González et al. (2000). For cloud detection, the algorithm of Koelemeijer et al. (2001) was used.

Comparisons of results from the dual view algorithm over land with data from collocated ground based sun photometers available from the AERONET (Holben et al., 1998) and from the Royal Meteorological Institute (KNMI) in The Netherlands were presented by Veefkind et al. $(1998,1999,2000)$ and by Robles González et al. (2000). The statistical analysis of these comparisons shows that the mean uncertainty of the retrieved AOD over land is 0.06 at $0.659 \mu \mathrm{m}$ with a standard deviation of 0.05 . The uncertainty is ascribed to the assumptions made in the algorithm and the differences of modeled aerosol types from the real aerosol type. Obviously over brighter surface the aerosol contribution will be determined with lower accuracy than over dark surfaces. However, unfortunately not enough sunphotometer measurements were available to estimate the uncertainty related to surface reflectance. Similarly, the single view algorithm yields an uncertainty of $0.04 \pm 0.01$ for the AOD over sea where the surface is dark and contributes very little to the TOA radiance. Over coastal waters the single view algorithm sometimes overestimates the AOD because the assumption of a 

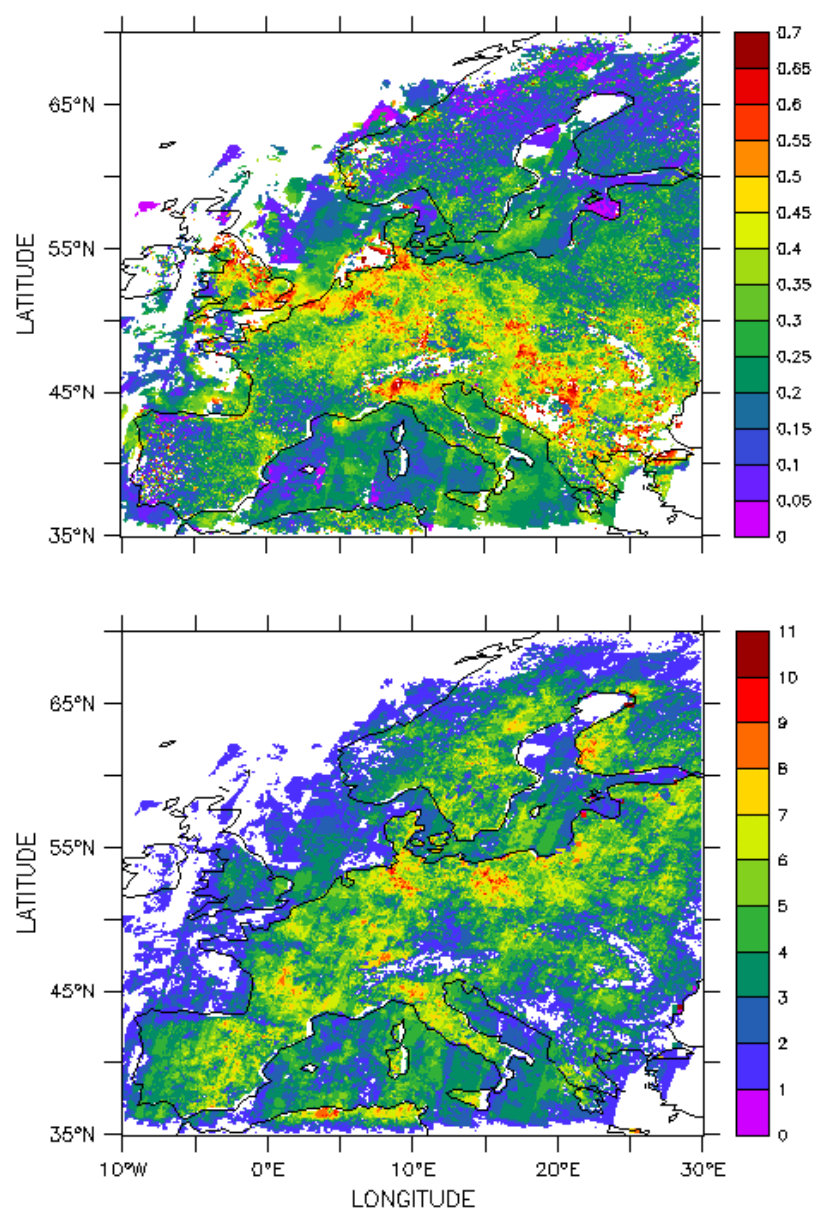

Fig. 1. Composite map of the (a) mean aerosol optical depth at $0.555 \mu \mathrm{m}$ over Europe for August 1997 and (b) the number of observations used to derive the mean value. AOD has been retrieved by application of the dual view algorithm to the ATSR-2 satellite data over land and the single view algorithm over ocean.

dark surface does not strictly apply. Nevertheless, the results are more accurate than those from the dual view algorithm.

In Fig. 1, satellite tracks are visible over the Baltic when the aerosol properties were significantly different between various ATSR-2 overpasses over the same area, in response to changing synoptic situations. For example, 19 August was a rather clean day with AOD values lower than 0.1, while on most other days the AOD values were much higher. Similarly, over the Mediterranean, the mean AOD in the track encompassing the Balearic Islands and Sardinia appears smaller than in the rest of the Mediterranean: on $30 \mathrm{Au}-$ gust, when the ATSR-2 passed over the area of the Balearic Islands, and on 31 August (over the Sardinia area) the AOD was less than 0.05 .

Data for direct comparison with the AOD retrieved over the European seas are not available. In Table 1, ATSR-2 derived AOD values are compared with data collected from research cruises on the Baltic (Kusmierczyk-Michulec et al.,
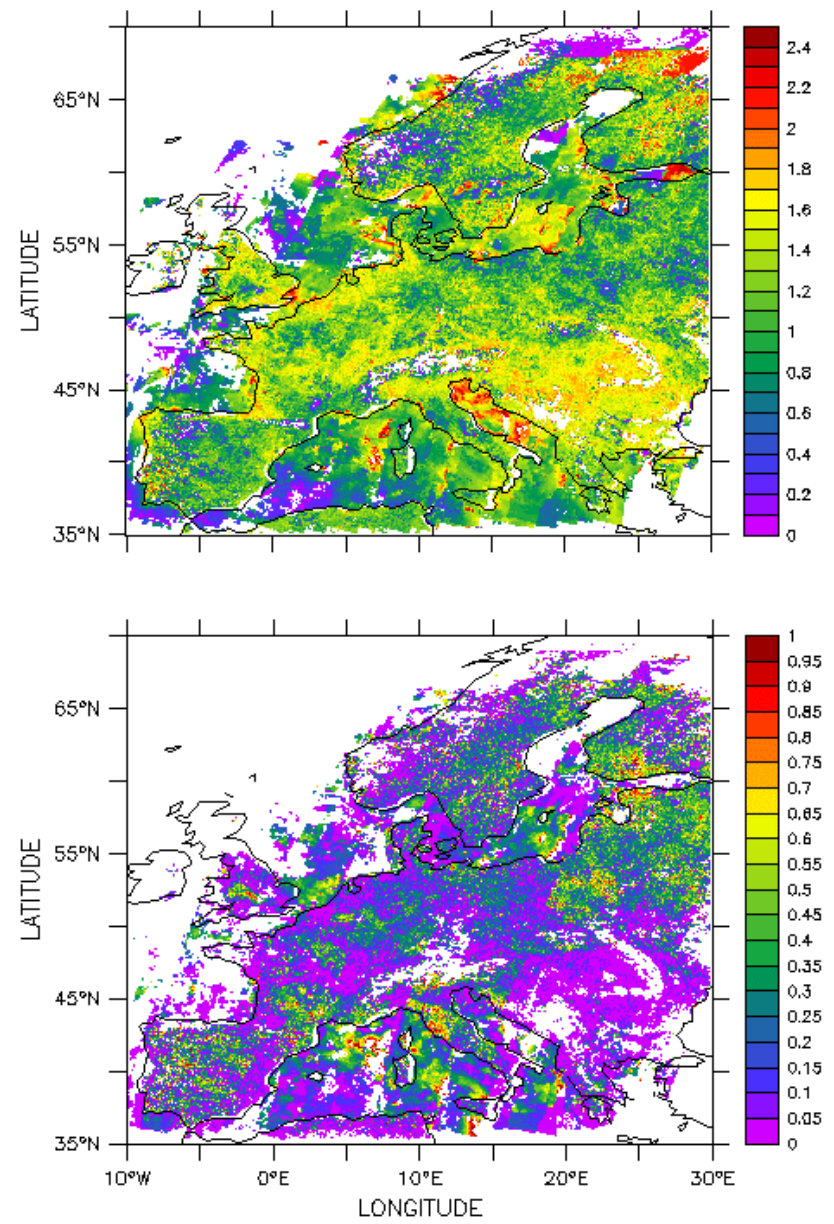

Fig. 2. (a) Mean Angström coefficients and (b) temporal variance over the number of clear sky overpasses for August 1997 (computed from the Angström law by linear regression).

1999b) and the Mediterranean (Smirnov et al., 1995), for different periods. Therefore they cannot directly be compared with the AOD values in Fig. 1, and are reproduced here because they show that the values retrieved from ATRS- 2 are consistent with other, independent, results.

\subsection{Angström coefficient}

The espectral dependence of the AOD follows the Angström law:

$\tau_{A}(\lambda) \propto\left(\frac{\lambda}{\lambda_{0}}\right)^{-\alpha}$,

where $\tau_{A}$ is the AOD at wavelength $\lambda, \lambda_{0}$ is a reference wavelength and $\alpha$ is the Angström coefficient. ATSR-2 has four channels $(0.555,0.659,0.865$ and $1.6 \mu \mathrm{m})$ which are used for aerosol retrieval. Angström coefficients were computed from the AOD at these wavelengths by linear regression. Using the same averaging procedure as for the AOD (see Sect. 2.1) yields the spatial distribution of the mean values of 
Table 1. AOD at $0.555 \mu \mathrm{m}$ and Angström coefficients derived from independent measurement over the Baltic and the Mediterranean seas

\begin{tabular}{|c|c|c|c|c|}
\hline BALTIC & AOD & $\alpha$ & Date & Reference \\
\hline Retrieved & $0.25 \pm 0.12$ & $1.4 \pm 0.7$ & August 1997 & This paper \\
\hline Measured & $0.23 \pm 0.11$ & 0.955 & Summer mean & $\begin{array}{c}\text { Kusmierczyk-Michulec } \\
\text { et al., 1999b }\end{array}$ \\
\hline MEDITERRANEAN & AOD & $\alpha$ & Date & Reference \\
\hline Retrieved & $0.20 \pm 0.11$ & $1.0 \pm 0.7$ & August 1997 & This paper \\
\hline Measured & $0.23 \pm 0.12$ & $1.6 \pm 0.5$ & August 1991 & Smirnov et al., 1995 \\
\hline
\end{tabular}

the Angström coefficients shown in Fig. 2a. Fig. 2b shows the temporal variance over the number of clear sky overpasses.

\subsection{Spatial variations}

The AOD values over land were discussed in Robles González et al. (2000). High AOD values of 0.5-0.6 are observed in a wide band across the continental European mainland from the North Sea coast stretching in south-easterly direction over the Balkans and Greece, and over the Po valley in Northern Italy. These high values are often associated with strongly industrialised areas with large emissions of aerosols and their precursor gases (Benkovitz et al. 1996). Strong spatial AOD gradients are observed around such areas, with sudden increases of a factor of 3 or more over relatively short distances, as well as gradual decreases over hundreds of kilometres downwind of source areas. The latter can be explained by the gradual removal of aerosols by dry deposition (the most effective removal process during August 1997 because dry conditions prevailed). In contrast, over other parts of Europe AOD values as low as 0.1-0.2 are observed, e.g. over Scandinavia, Central Spain, Southern France and Russia.

The Angström coefficients show a similar pattern, which indicates that large AOD values are mainly due to the formation of sub-micron aerosols in the accumulation mode, such as the ammonium salts of sulphate and nitrate. Over the cleaner areas, with low AOD and Angström coefficients, the relatively high variances in the latter indicate that the results carry a large uncertainty. This is caused by the low AOD values (see Fig. 1a) which do not allow for an accurate fit of Eq. 1. It is noted that variances in the AOD values are rather low, generally smaller than 0.05 at $0.555 \mu \mathrm{m}$.

The Angström coefficients over some of the most polluted areas, such as Belgium, The Netherlands and the Northwest of Italy vary between 0.8 and 1.6. This range is larger than the typical values of 1.13 to 1.4 indicated by Hess et al. (1998) for continental polluted air masses containing insoluble particles, water-soluble particles such as sulphate and nitrate aerosols, and soot. Obviously, the observed wider range of values is due to the presence of other types of aerosol. Fig- ure $2 \mathrm{a}$ is an average of a maximum of 11 days and thus the averaged Angström coefficients can be affected by different situations that occurred in August 1997. The regional variation of Angström coefficients in Europe is an indication of different aerosol size distributions and likely also different chemical composition.

Over water, the AOD is usually smaller than over land. However, in areas downwind from continental aerosol sources the AOD can be rather high. For instance, over the North Sea, AOD values up to 0.6 were observed due to advection of aerosol from industrial and urban areas in the UK and in Western Europe. Over the Baltic Sea, mean AOD values from 0.15 to 0.4 were observed, with values averaging around 0.3 over the south-west part and values lower than 0.2 over the south-eastern part.

The Angström coefficients over the Baltic varied between 1 and 2 (Table 1), in contrast to expected values between 0.08 and 0.12 for clean maritime air masses, or 0.35 to 0.41 for polluted maritime air masses (Hess et al., 1998). However, Kusmierczyk-Michulec et al. (1999a) show Angström coefficients over the Baltic Sea for July 1997 with values up to 1.7 for continental air masses and up to 1.9 for continentalmaritime air masses. Over the Mediterranean, the Angström coefficients are up to 1.6 (Fig. 2a), in good agreement with data reported by Smirnov et al. (1995) for August 1991 (Table 1).

\section{Sulphate and nitrate concentrations modelled by the LOTOS chemical transport model}

\subsection{Calculation of sulphate and nitrate aerosol fields}

In view of the large spatial variations of both the AOD and the Angström coefficients, and the observed association with anthropogenic emissions of precursors gases, a chemistry transport model was applied to actually calculate the aerosol concentration fields over Europe. For this purpose the LOTOS model (LOng Term Ozone Simulation) (Builtjes, 1992; Hass et al., 1997) has been used. Calculations have been performed for the month of August 1997. The model is a 3-D Eulerian grid model with a horizontal grid resolution of 

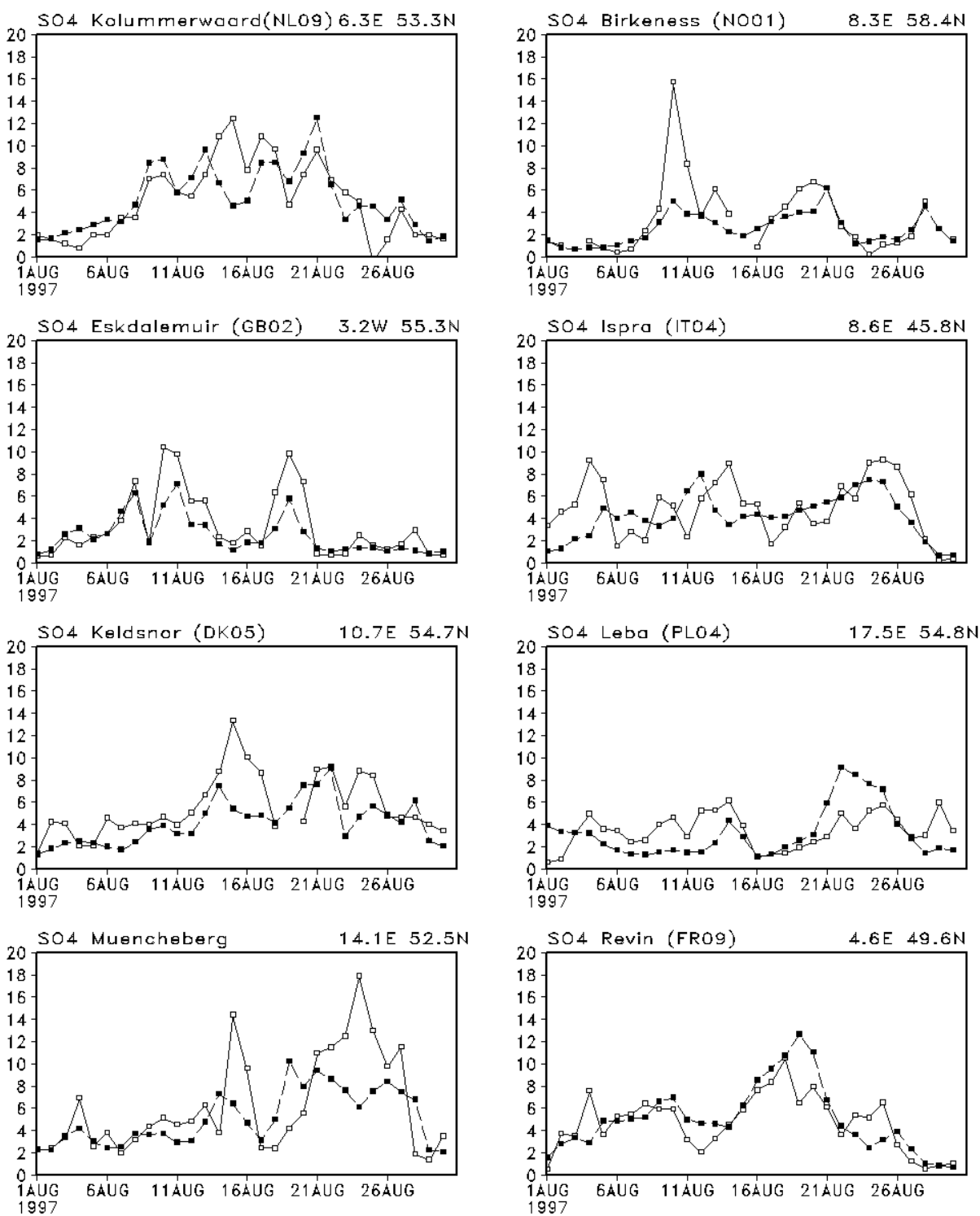

Fig. 3. Daily variation of modelled (filled squares) and measured (empty squares) sulphate and (total) nitrate concentrations in $\mu \mathrm{g} / \mathrm{m}^{3}$ at selected locations in Europe. Data obtained from EMEP (2002) (www.emep.int) and Zimmerling et al. (2000).

$0.25 \times 0.5$ latitude-longitude. The LOTOS model is restricted to the lower troposphere and has 4 vertical layers up to about $3.5 \mathrm{~km}$ (depending on mixing layer height). More than $90 \%$ of the aerosol contributing to the AOD usually occurs up to this height (Ten Brink et al., 2001). LOTOS contains an implicitly assumed constant size distribution for accumulation mode particles. A full description of the model, including inorganic aerosols is presented in Schaap et al. (2003).

The meteorological input is diagnostic, derived from ECMWF using procedures developed by the Free University of Berlin. The emission input is based on CORINAIR (EEA, 1996). The gas-phase chemistry used in LOTOS is a modified version of the Carbon Bond IV mechanism (CBM-
IV) (Whitten et al. 1980). Biogenic VOC (Volatile Organic Compounds) emissions are also included. LOTOS has been thoroughly tested for ozone, a comparison of LOTOS with other photo-oxidant dispersion models is presented in Hass et al. (1997).

In order to calculate (ammonium) sulphate and (ammonium) nitrate concentration fields over Europe, LOTOS has been extended with the Isorropia aerosol module (Nenes et al. 1998). Isorropia describes the partitioning of nitrate between the gas and aerosol phase. Ammonia plays a key role in this process. At first ammonia reacts irreversibly with sulphuric acid to form ammonium sulphate:

$\mathrm{NH}_{3}(\mathrm{~g})+\mathrm{H}_{2} \mathrm{SO}_{4}(\mathrm{aq}) \rightarrow \mathrm{NH}_{4} \mathrm{HSO}_{4}(\mathrm{aq}, \mathrm{s})$ 

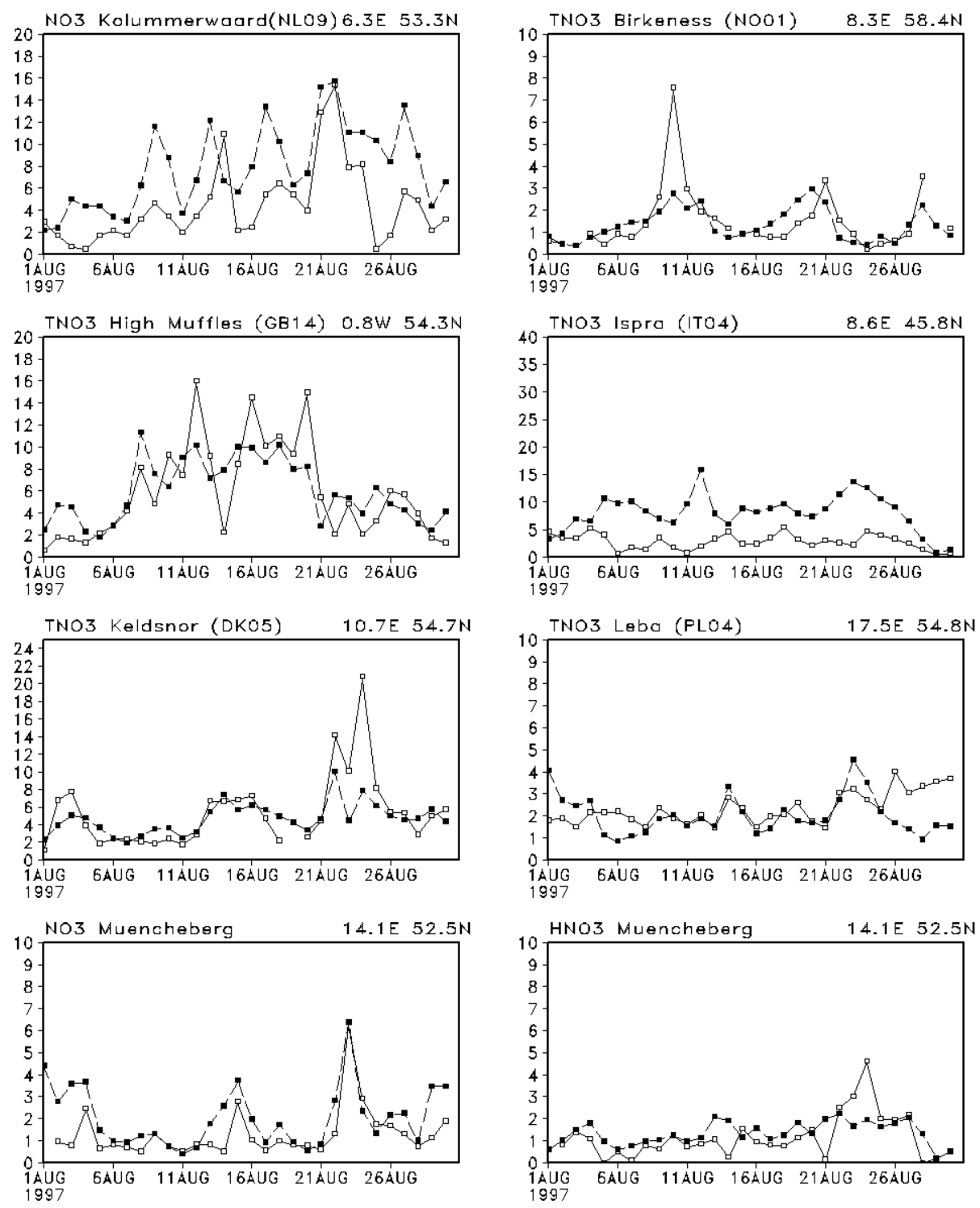

Fig. 3. Continued

$\mathrm{NH}_{3}(\mathrm{~g})+\mathrm{NH}_{4} \mathrm{HSO}_{4}(\mathrm{aq}, \mathrm{s}) \rightarrow\left(\mathrm{NH}_{4}\right)_{2} \mathrm{SO}_{4}(\mathrm{aq}, \mathrm{s})$.

When sulphuric acid is completely neutralised, excess ammonia (further denoted as free ammonia) can react with nitric acid to form (semi-volatile) ammonium nitrate:

$\mathrm{NH}_{3}(\mathrm{~g})+\mathrm{HNO}_{3}(\mathrm{~g}) \Leftrightarrow \mathrm{NH}_{4} \mathrm{NO}_{3}(\mathrm{aq}, \mathrm{s})$.

This equilibrium is very sensitive to ambient conditions. The equilibrium constant decreases strongly with decreasing temperature and increasing relative humidity (Mozurkewich, 1993). Thermodynamic equilibrium between the gas and aerosol phase is assumed at all times. The model does not incorporate sea salt or dust. Caution is therefore advised when applying the equilibrium module over coastal and arid regions (Zhang et al., 2000). Calculations with the LOTOS model have been performed over the month of August 1997, with a 7 days spin-up period.

\subsection{Evaluation of modelling results}

The sulphate-nitrate-ammonium concentrations calculated with LOTOS have been thoroughly compared with available ground level observations for the whole year of 1995 (Schaap et al., 2003). A detailed discussion on the model performance is presented in Schaap et al. (2003). In this paper results for August 1997 are shown in comparison with available ground level observations.

Evaluation of the model results is only possible when reliable observational data are available. However, measurements of nitrate are sparse and prone to artefacts, an overview 

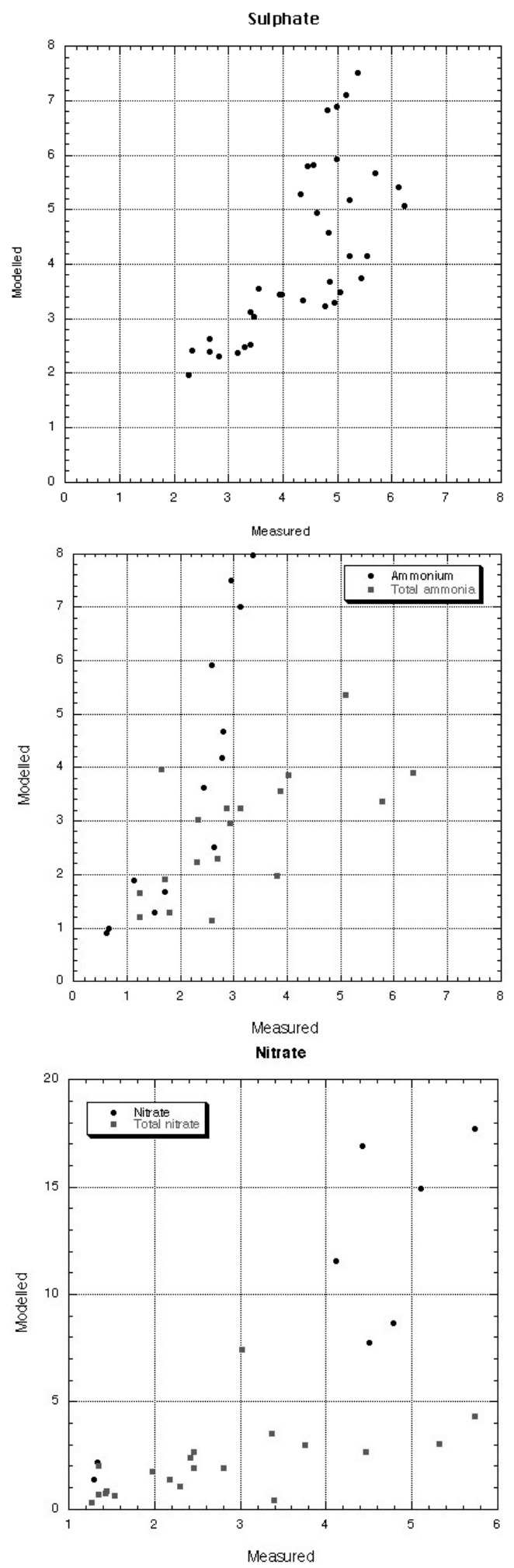

Fig. 4. Scatter plot of monthly averaged modelled and measured concentrations of sulphate, nitrate, ammonium and the sum of aerosol and gaseous nitrate and ammonia in $\mu \mathrm{g} / \mathrm{m}^{3}$.

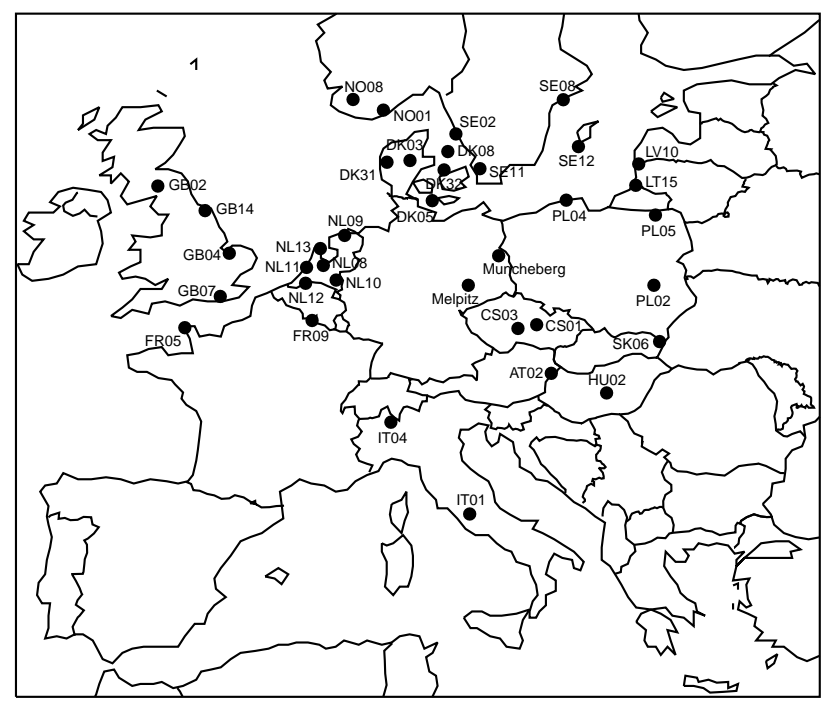

Fig. 5. Geographic map with the location of the experimental stations.

of methods used in Europe and an assessment of available data is presented in Schaap et al. (2002a). Serious problems are the volatility of ammonium nitrate and the reactivity of nitric acid. During summer, severe evaporation of ammonium nitrate may occur from inert filters. Data obtained from inert filters are therefore not used here. Reliable data are only obtained with devices that remove nitric acid prior to aerosol sampling and stabilize ammonium nitrate against evaporation, e.g. denuder filter combinations. Data from cellulose filters are interpreted as total nitrate, i.e. the sum of aerosol nitrate and gaseous nitric acid. At sites where both cellulose and an impregnated total nitrate filter are used, we chose to use the data from the latter.

Comparisons between model results and selected experimental data for August 1997 are presented in Figs. 3 and 4. In Fig. 5 a geographic map of the experimental sites is shown. Figure 3 shows time series of sulphate concentrations at eight locations, the sum of nitrate and nitric acid (TNO3) at five locations, NO3 at two locations and $\mathrm{HNO} 3$ at one location. In general the model and experimental values for the concentrations trace quite well, albeit that the peak values are often not well reproduced by the model. In some cases the model tends to predict lower values but there is no apparent bias in the time series except for TNO3 at Ispra $\left(45.8^{\circ} \mathrm{N}, 8.6^{\circ} \mathrm{E}\right)$ where the experimental values are consistently lower than the model values. The scatter plots of monthly averaged modelled and experimental values for sulphate, nitrate, ammonium, total nitrate and total ammonia are given in Fig. 4. The scatter plot in Fig. 4a shows that the calculated and measured monthly mean concentrations of sulphate compare favourably. Model values are generally within $40 \%$ of the measured concentration. The values for total ammonia (Fig. 4b) compare even better and generally agree within $10-20 \%$. The vast majority 

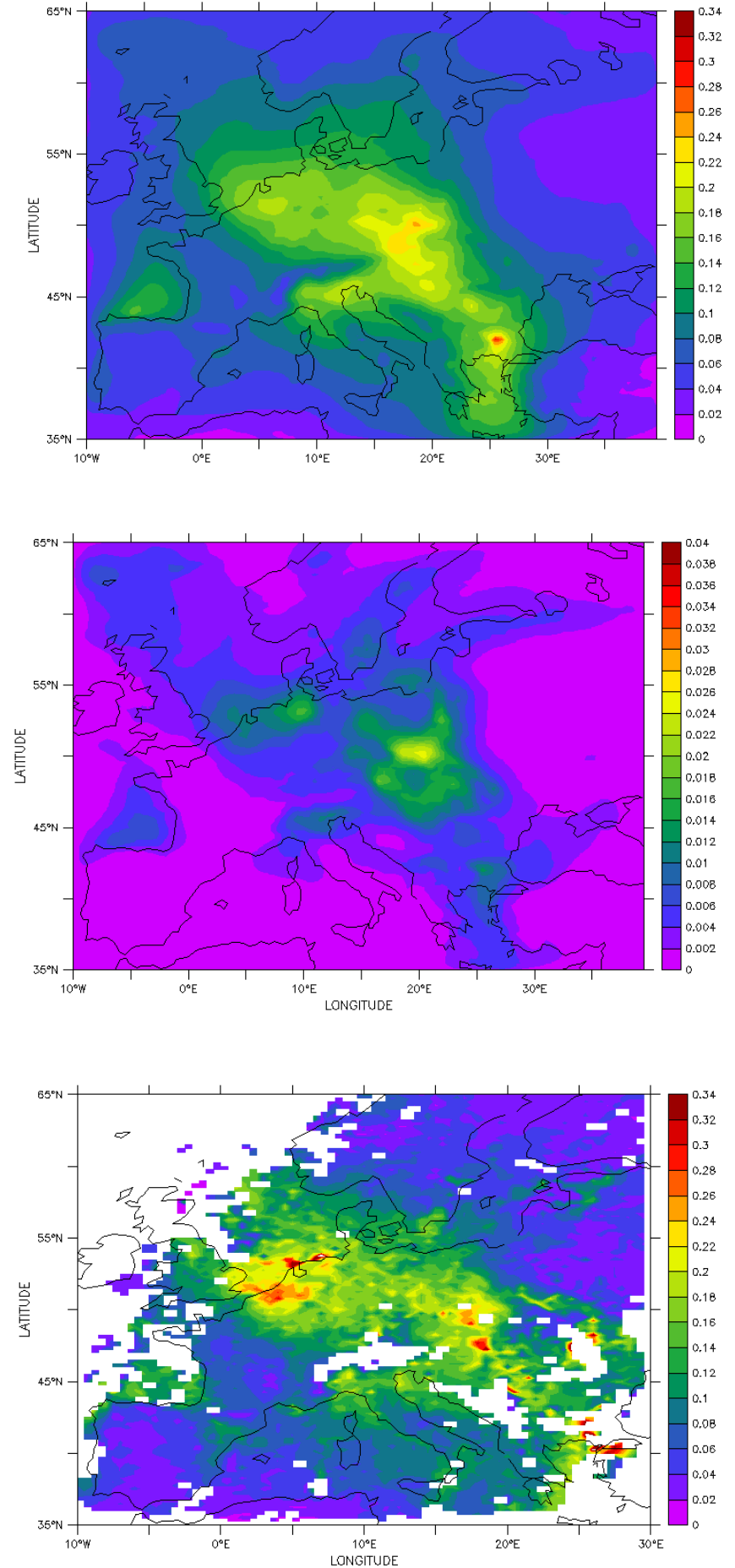

Fig. 6. Aerosol optical depth due to sulphate aerosols computed with the LOTOS model. (a) shows the mean aerosol optical depth for the whole month of August 1997 at $0.550 \mu \mathrm{m}$. (b) shows the variance. (c) shows the mean modelled sulphate AOD for the times when satellite data are available.
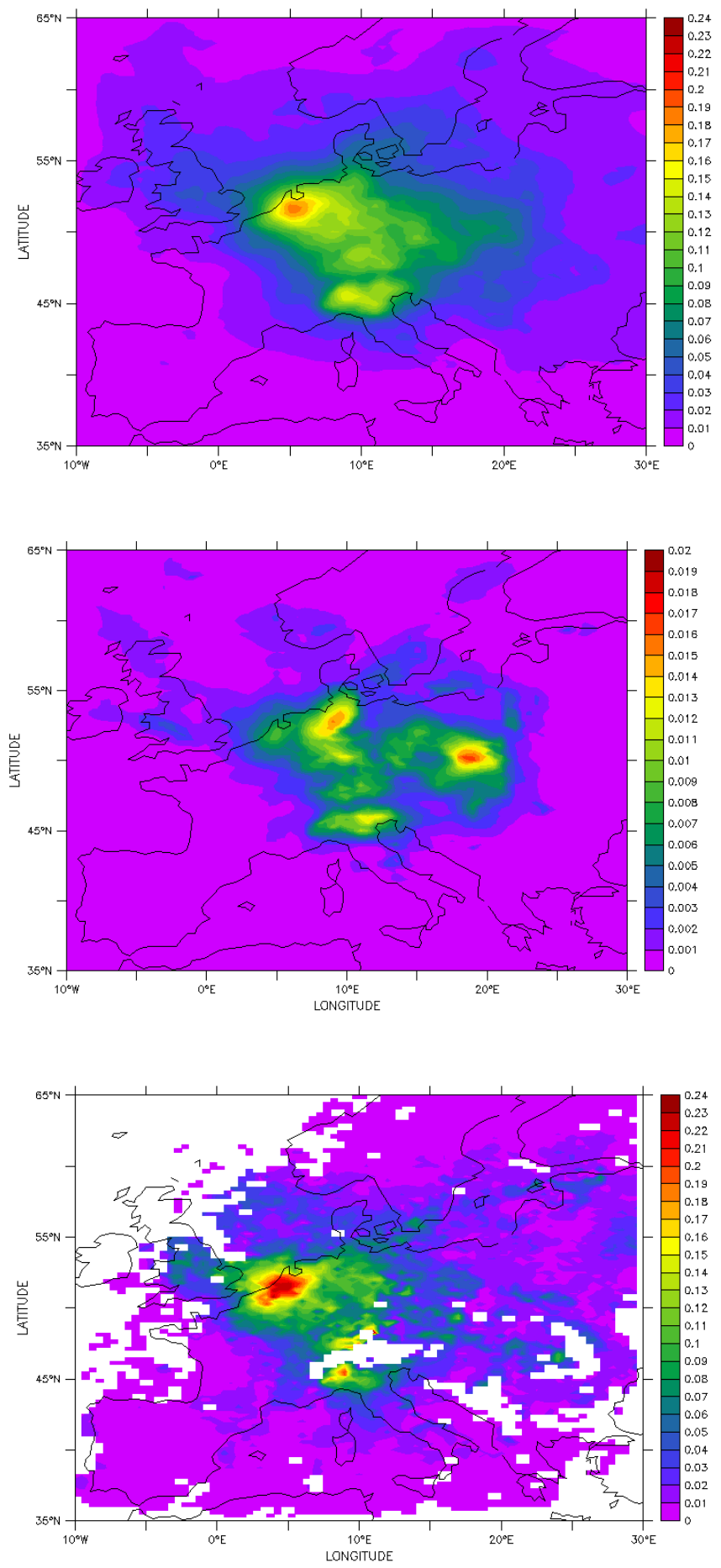

Fig. 7. Aerosol optical depth due to nitrate aerosols computed with the LOTOS model. (a) shows the mean aerosol optical depth for the whole month of August 1997 at $0.550 \mu \mathrm{m}$. (b) shows the variance. (c) shows the mean modelled nitrate AOD for the times when satellite data are available. 
of the nitrate data (Fig. 4c) stem from total nitrate samplers. The values for total nitrate compare favourably. However for nitrate aerosol the comparison is less good. Nevertheless, for nitrate aerosols only 8 data points are available, 6 of which in the Netherlands. In the Netherlands the concentrations of nitrate (and those of the associated ammonium) are overestimated by the model by a factor of $2-3$. The overestimation in the Netherlands (and also at Ispra) is associated with very high concentrations during the night. The detailed comparison of the data for 1995 (Schaap et al., 2003) shows that nitric acid concentrations in coastal areas are overestimated by the model, which was partly attributed to the fact that model does not include sea salt which is a sink for nitric acid through the chlorine replacement reaction. However, data lack to assess the partitioning and cat-ion association of nitrate in these areas. At a continental site, DE99 (Muencheberg) (Zimmerling et al., 2000), the partitioning of nitrate between the gaseous and aerosol phase seems to be rather well simulated (see Fig. 3).

\subsection{Conversion of modelled aerosol mass concentrations to aerosol optical depth}

The AOD was computed from the dry aerosol mass concentrations derived from the LOTOS model using the approach of Kiehl and Briegleb (1993):

$\mathrm{AOD}_{i}(\lambda)=f(\mathrm{RH}, \lambda) \cdot \alpha_{i}(\lambda) \cdot B_{i}(\lambda)$,

where $\alpha_{i}(\lambda)$ is the mass extinction efficiency of the compound $i ; B_{i}$ is the column burden of the compound $i$, obtained from the LOTOS model; $f(\mathrm{RH}, \lambda)$ is a function describing the variation of the scattering coefficient with relative humidity $(\mathrm{RH})$ and wavelength $(\lambda)$.

To compute $\alpha_{i}(\lambda)$ for dry particles, a Mie (Mie, 1908) code has been used, assuming the aerosol size distribution to be log-normal, with a geometric mean radius of $0.05 \mu \mathrm{m}$, a geometric standard deviation of 2.0 and a sulphate dry particle density of $1.7 \mathrm{~g} \mathrm{~cm}^{-3}$ (Kiehl and Briegleb, 1993).

Most aerosol particles absorb or release water vapour when the relative humidity $(\mathrm{RH})$ changes. Thus the size and composition of the particles change, resulting in different light scattering properties. To account for the variation of the aerosol scattering coefficient with $\mathrm{RH}$, the factor $f(\mathrm{RH}, \lambda)$, derived from humidity controlled nephelometry (Veefkind et al., 1996), is used in Eq. (5). Effects due to hysteresis (e.g. Tang, 1997) are not accounted for. The wavelength dependence of $f(\mathrm{RH})$ can be ignored (Veefkind et al., 1999). The scattering calculations were made with $\mathrm{RH}$ values taken from the analysed meteorological data file that is used as input to the LOTOS model, including the variations of $\mathrm{RH}$ with height.

\section{Estimated contributions of $\mathrm{SO}_{4}$ and $\mathrm{NO}_{3}$ to the total AOD}

Daily maps of sulphate and nitrate induced AOD were computed from the calculated aerosol fields. Monthly averages for a wavelength of $0.55 \mu \mathrm{m}$ are presented in Figs. 6 and 7. Because the satellite derived AOD values are available only for a specific time, only the model values obtained at the same time were included in the average. Figure 6a shows the variability of the sulphate induced AOD over Europe for the whole month August 1997, in Fig. 6b the variance can be observed. In Fig. 6a values of up to 0.25 occur mostly over Central Europe and Greece. Over north western Europe, the North of Italy, the Balkans and over the Bay of Biscay AOD values up to 0.2 are observed. The high values of the Gulf of Biscay are due to aerosols advected from the north of Spain. Modelled AOD values decrease gradually towards the more remote areas, such as northern Scandinavia. Figure 6c shows the mean modelled sulphate AOD only for the times when satellite data are available. Sulphate AOD fields show higher variability in Fig. 6c than Fig. 6a, in better agreement with satellite results. Higher sulphate AOD values can be observed over the Netherlands and some areas over Eastern Europe. It should be emphasised that these results (Fig. 6c as well as Fig. 1a) represent only good weather conditions (cloud free situations).

Mean nitrate AOD values (Fig. 7a) are significant over parts of Europe. In some areas over The Netherlands and Italy the LOTOS calculated nitrate induced AOD is up to 0.2 and 0.15, respectively. Over central Europe nitrate AOD is about 0.1-0.12. Experimental data show that, in the summer, nitrate in The Netherlands is mainly associated with ammonium occurring in the accumulation mode (Schaap et al., 2002a). Apparently, in this time of the year, the moderate temperatures and high relative humidity in the Netherlands (as compared to other parts of Europe) in combination with excess ammonia, promote the formation of ammonium nitrate (cf. the brief discussion in Sect. 3.1 on the reaction mechanisms and the effect of temperature on the equilibrium constant) (Eq. 4). Figure 7b shows the variance of the nitrate AOD. The mean modelled nitrate AOD for the time when satellite data are available is shown in Fig. 7c. As in Fig. 6c, this figure shows higher spatial variation than Fig. 7a. Over the Netherlands and the Po valley higher AOD can be observed.

The sum of the calculated sulphate and nitrate AOD values from Fig. $6 \mathrm{c}$ and $7 \mathrm{c}$ show similar patterns as the total AODs retrieved from satellite data in Fig. 1a except over the Netherlands where modelled nitrate AOD values are overestimated. The reason of this overestimation was already discussed. The satellite derived values must be higher than those from the model because the satellite measures the total atmospheric column and other aerosol types than sulphates and nitrates, such as organics, sea salt, and dust, can be present in the atmospheric column at the moment of the satellite overpass. 


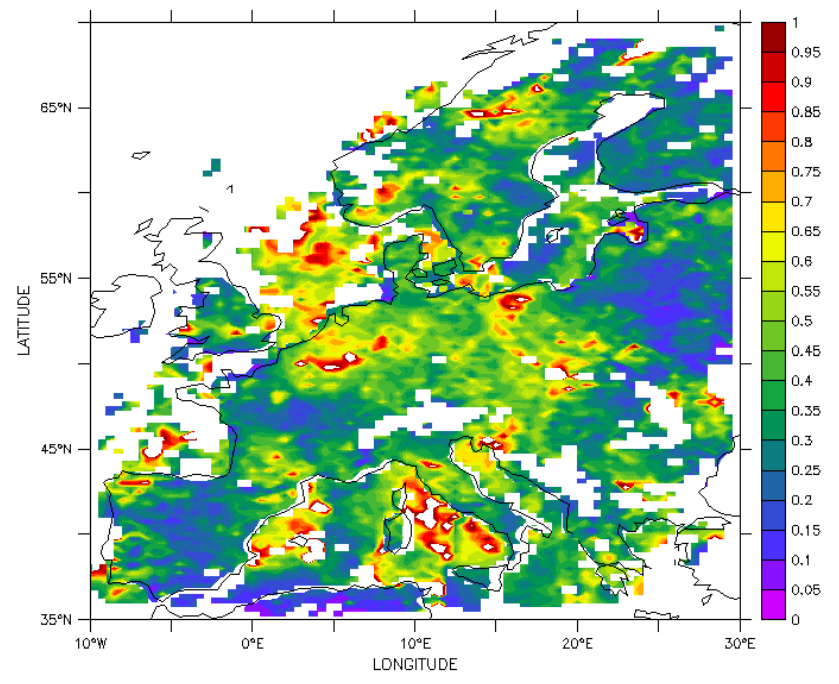

Fig. 8. The ratio of sulphate aerosol induced AOD computed from the LOTOS model to the total aerosol optical depth retrieved from satellite data with the dual view algorithm.

From comparison of the calculated and retrieved AODs, the relative contributions of sulphate and nitrate aerosol to the total AOD can be estimated, within the inherent uncertainties of both data sets. Results for sulphate and nitrate contributions, for cloud free conditions, are presented in Figs. 8 and 9 , respectively.

The results in Fig. 8 show that sulphate contributes up 40 to $60 \%$ to the total AOD over most parts of Europe. Over the Netherlands, some parts of Germany, Poland, Spain, and Croatia contributions up to $70 \%$ are found. Over some parts of France, Southern Spain, and Eastern Europe sulphate contributes around $30 \%$. Over the Scandinavian countries higher sulphate contributions than expected are observed. Natural contributions such as dust aerosols or plants expel are higher in the south than in the north, due to the warmer and sunnier conditions. This leads to higher anthropogenic influence in the north than in some southern areas such as the south of France or Spain.

Figure 9 shows that the contribution of nitrate to the total AOD is significant over some parts of Europe with contributions exceeding $10 \%$. Over western and central Europe and northern Italy contributions up to $30 \%$ are observed. Over the Netherlands the nitrate contribution reaches values up to $60 \%$. This contribution is overestimated as already explained in Sect. 3.2 due to the overestimation of nitrate concentrations by the model.

The combined effect of sulphate and nitrate on the AOD is shown in Fig. 10, to visualise the degree and location of agreement between model and measurements. Obviously, in areas where the ratio of modelled to measured AOD is larger than 1 , the modelled aerosol concentrations are too high. This happens for instance over the Netherlands where values of about 1.2-1.3 are due to the overestimation of the

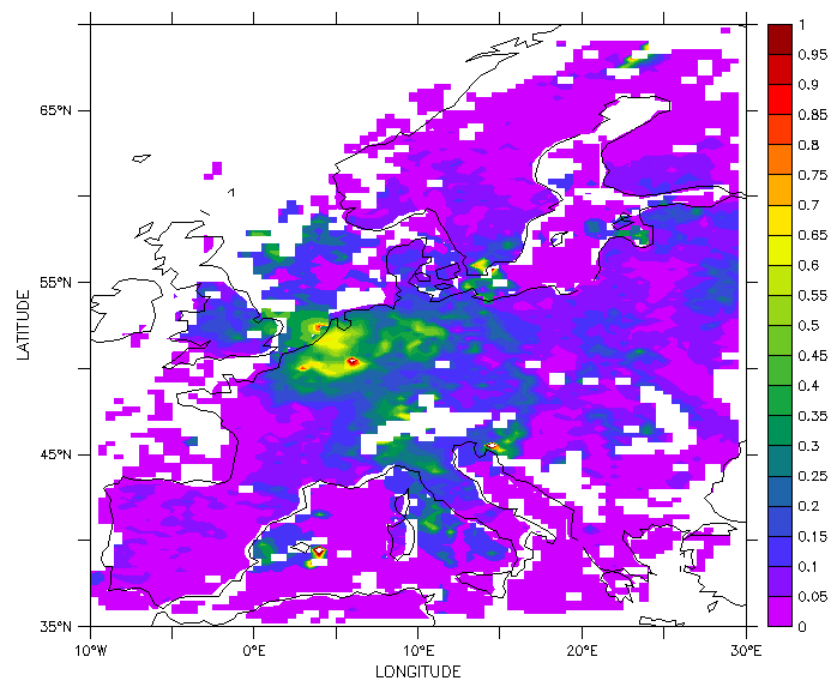

Fig. 9. The ratio of nitrate aerosol induced AOD computed from the LOTOS model to the total aerosol optical depth retrieved from satellite data with the dual view algorithm.

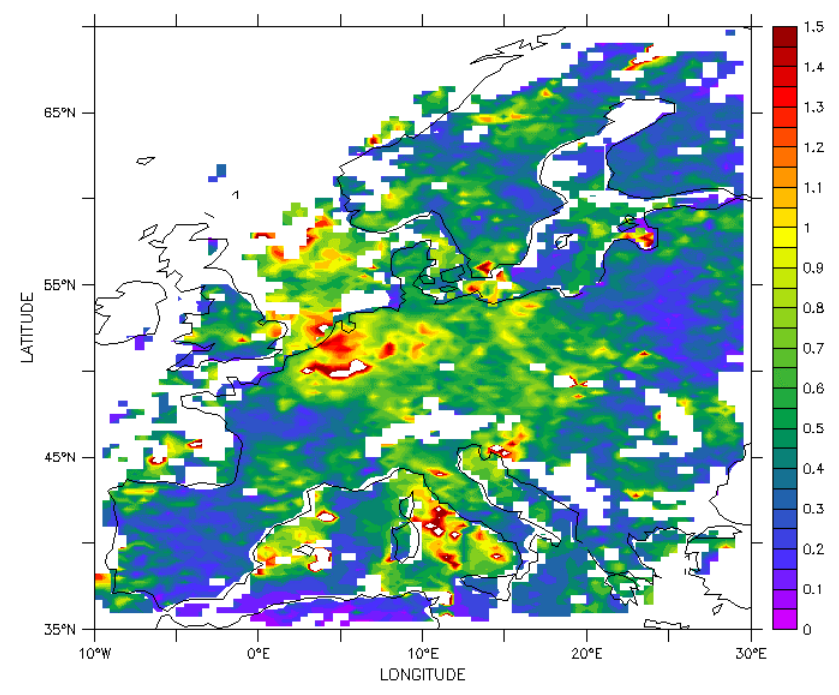

Fig. 10. The ratio of the modelled AOD due to the combined effects of sulphate and nitrate to the total aerosol optical depth retrieved from satellite data with the dual view algorithm.

nitrate load (see Sect. 3.2). In other areas such as over central Europe, the south of France and the north of Italy values of about $0.5-1$ are observed. Ratios lower than 0.5 are observed, e.g. most of Spain, the south of Italy and Eastern Europe, which indicates that sulphate and nitrate contribute less than 50\% to the total AOD. In these areas other aerosols such as primary carbonaceous, sea salt or dust, need to be accounted for to explain the aerosol radiation effects. Primary carbonaceous aerosols are planned to be included in the LOTOS model in the near future. 


\section{Discussion}

The total AOD consists of contributions of various aerosol types. The LOTOS model has been used to evaluate the contributions of sulphate and nitrate, the most abundant aerosol types over Western Europe, to the total AOD. Only few data are available for comparison.

The mean AOD presented in Fig. 1 results from satellite overpasses, every third day, in cloud free situations. The monthly averaged AOD values are in good agreement with results from ground based sunphotometer data (Robles González et al., 2000).

Direct measurements of the relative contributions of sulphate and nitrate aerosols to the total aerosol light-scattering were made in Petten, the Netherlands, during the summer of 1994 (Ten Brink et al., 1996). These authors conclude that in the summer, the contribution of sulphate and nitrate aerosols are of similar magnitude and between 30 and $40 \%$ of the total aerosol light-scattering. In spite of the significant reduction of $\mathrm{SO}_{2}$ emissions in the last 15 years, these results are similar to earlier estimates of 38\% by Diederen et al. (1985) who used measurements in Delft, The Netherlands, in 1985. The fact that Diederen et al. (1985) measured in Delft which is an industrial area while Ten Brink et al. (1996) measured in a rural area in the north of the Netherlands, might explain this similar sulphate contributions. Despite of the reduction in the emissions, the relative contribution of sulphate to the total light scattering over The Netherlands derived from satellite measurements and model results is around $60 \%$. To explain the apparent discrepancy between this figure and the previous measurements, a close examination of the comparison of the model and experimental results shows that for the sites over the Netherlands the model prediction were about $30 \%$ too high. Hence also the model AOD is about $30 \%$ too high. Correcting for this factor brings the satellite derived results close to the former measured values. The modelling of the ammonium nitrate concentrations is still associated with large uncertainties (Metzger et al., 2002; Schaap et al., 2003). In addition, data for model verification are sparse. Data to validate the diurnal cycle of the nitrate concentrations, which is expected to be strong due to its semi-volatile nature are not available. Therefore, the uncertainty in the modelled AOD due to nitrate is large. For nitrate, relative contributions up to $60 \%$ were obtained over the Netherlands. These high values do indicate the regional importance of nitrate during summer, which has also been established from local measurements. This value is higher than derived from local measurements. The overestimation of modelled nitrate levels occurs in regions with very high ammonia emissions, e.g. the Netherlands and the Po Valley. The knowledge on emissions of ammonia and its fate shortly after emission is still limited, causing significant uncertainties in the model input and description. Sub-grid phenomena such as the strong vertical gradient of ammonia concentrations near the ground and re-emission cannot be reproduced by the model. As a consequence we likely underestimate the dry deposition of ammonia directly after emission. The sensitivity of modelled ammonium nitrate levels to changes in ammonia emissions is large and, hence, more knowledge is needed to correctly simulate ammonia (and ammonium nitrate) burdens in these regions.

For most other areas no experimental data is available to compare with the results discussed in Sect. 4. In addition, the comparison presented above contains at most 11 data points, which are obviously greatly influenced by the occurring meteorology. Therefore only trends can be indicated and uncertainties in emissions and model results, as well as experimental uncertainties, need to be accounted for. Therefore this study is regarded as a demonstration of the complementarity use of aerosol retrievals and model results. A model study on the contribution of the most important aerosol types, such as sulphate, dust, and carbonaceous particles, to the total AOD is presented in Tegen et al. (1997). The results show that the contribution of sulphate to the total modelled AOD over Western Europe is between 25\% and 36\% depending on the amount of absorbing aerosols, mainly soil dust and black carbon. This result is in good agreement with the values presented above. Over the ocean, the authors also compared model results with the AOD retrieved from data from the AVHRR, leading to the conclusion that globally the contribution of sulphate to the total retrieved AOD over the ocean is $40-50 \%$. This applies mainly to open ocean where the influence of continental aerosol is rather small. In Fig. 8 it can be observed that sulphate contribution can be up to 0.60.8 over the North Sea and some areas of the Mediterranean Sea probably due to anthropogenic aerosols advected from inland. Jeuken et al. (2001) used the AOD values for August 1997 retrieved by Robles-Gonzalez et al. (2000) to validate the results from the global model TM3, i.e. calculated sulphate and nitrate concentrations, over Europe. These authors found that 'the average observed AOD is more than a factor of two larger than the average simulated AOD' and attributed missing species to organic and mineral aerosol. The current results show the large spatial variability of the sulphate and nitrate contributions to the total AOD, which is not resolved by coarse resolution of a global model.

\section{Conclusions}

The above results are an illustration of the complementary use of three-dimensional chemical transport models and satellite observations. The models can provide information on the temporal and spatial (vertical and horizontal) distributions as well as chemical composition of the different types of aerosol. Satellites can be used to retrieve information on the aerosols.

The aerosol optical depth and the Angström coefficient can be retrieved from ATSR-2 data over land and over sea. The ATSR-2 results compare favourably with data obtained from independent methods, such as ground based measurements, 
models and retrievals from other instruments on other satellites. High AOD values at $0.555 \mu \mathrm{m}$ of around $0.5-0.6$ and Angström coefficients between 0.8 and 1.6 found over the most industrialised areas indicate the presence of small particles from anthropogenic sources i.e. sulphate and nitrate aerosols. AOD and Angström coefficient values around 0.23 and 1.2 respectively found over the seas are presumably due to larger particles such as sea spray aerosols. The complementary use of satellite data and model results allows deduction of information on the contribution of the individual aerosol components to the total AOD. Similar trends are observed in the spatial variations of the calculated and retrieved AOD values. For this specific month, the contribution of sulphate to the total light scattering varies from less than $30 \%$ over the cleanest areas to $70 \%$ over the most polluted areas in central Europe.

Taking into account the uncertainties in the calculated nitrate concentrations discussed above, nitrate may contribute up to about $10-15 \%$ in most of Europe. Values comparable to those of sulphate are observed over The Netherlands and Northern Italy. Although the modelled nitrate contributions are uncertain it does indicate the regional importance of nitrate in these regions during summer, which has been established earlier from local measurements in the Netherlands by Ten Brink et al. (1996). Complementary satellite data and model results allow for evaluation of the effect of various aerosol types on regional scales.

Acknowledgements. The work described in this paper is supported by the Netherlands Space Research Foundation (SRON), under contract EO-037 and the Dutch National Remote Sensing Board. The ATSR-2 data was kindly provided by the European Space Agency (ESA-ESRIN). The authors thank D. Tanré from the Laboratoire d'Optique Atmospherique (LOA), Université of Lille and D. Zibordi for the AERONET Sun/sky radiometer data, and P. Stammes from the Royal Netherlands Meteorological Institute (KNMI) for making available the sunphotometer data from De Bilt. The Ferret analysis package was used in the preparation of this work (available at http://ferret.wrc.noaa.gov). Ferret was developed by the NOAA-PMEL, Ocean Climate Research Division. Comments by the anonymous reviewers significantly improved the data presentation.

\section{References}

Benkovitz, C. M., Scholtz, M. T., Pacyna, J., Tarrason, L., Dignon, J., Voldner, E. C., Spiro, P. A., Logan, J. A., and Graedel, T. E.: Global gridded inventories of antropogenic emissions of sulphur and nitrogen, J. Geophys. Res., 101, 29 239-29 253, 1996.

Builtjes, P. J. H.: The LOTOS - Long Term Ozone Simulation - project, Summary report, TNO-report, TNO-MW-R92/240, 1992.

De Rooij W. A., and Van der Stap, C. C. A. H.: Expansion of Mie scattering in generalized spherical functions, Astron. Astrophys., 131, 237-248, 1984.
Diederen, H. S. M. A., Guicherit, R., and Hollander, J. C. T.: Visibility reduction by air pollution in The Netherlands, Atmospheric Environment, 19, 2, 377-383, 1985.

Durkee, P. A., Jensen, D. R., Hindman, E. E., and VonderHaar, T. H.: The relationship between marine aerosols and satellite detected radiance, J. Geophys. Res., Vol. 91, 4063-4072, 1986.

Durkee, P. A., Nielsen, K. E., Smith, P. J., Russell, P. B., Schmid, B., Livingston, J. M., Holben, B. N., Tomasi, C., Vitale, V., Collins, D., Flagan, R. C., Seinfeld, J. H., Noone, K. J., Ostrom, E., Gasso, S., Hegg, D., and Russell, L. M.: Regional aerosol optical depth characteristics from satellite observations: ACE-1, TARFOX and ACE-2 results, Tellus, 52, 2, 484-497, 2000.

EEA (European Environmental Agency): European topic centre air emissions, CORINAIR 1994, summary report, 1996.

Flowerdew, R. J. and Haigh, J. D.: An approximation to improve accuracy in the derivation of surface reflectances from multi-look satellite radiometers, Geophys. Res. Let., 23, 1693-1696, 1995.

Hass, H., Builtjes, P. J. H., Simpson, D., and Stern, R.: Comparison of model results obtained with several European air quality models, Atmospheric Environment, 31, 3259-3297, 1997.

Hess, M., Koepke, P., and Schult, I.: Optical properties of aerosols and clouds: The software package OPAC, Bulletin of the American meteorological society, 79, 5, May 1998.

Holben, B. N., Eck, T. F., Slutsker, I., Tanre, D., Buis, J. P., Setzer, A., Vermote, E., Reagan, J. A., Kaufman, Y. J., Nakajima, T., Lavenu, F., Jankowiak, I., and Smirnov, A.: AERONET A Federated Instrument Network and Data Archive for Aerosol Characterisation, Remote Sensing of the Environment, 66, 1-16, 1998.

Jeuken, A., Veefkind, J. P., Dentener, F., Metzger, S., and Robles González, C.: Simulation of the aerosol optical depth over Europe for August 1997 and a comparison with observations, J. Geophys. Res., 106, 28 295-28311, 2001.

Kaufman, Y. J., Tanre, D., Remer, L. A., Vermote, E. F., Chu, A., and Holben, B. N.: Operational remote sensing of tropospheric aerosols over land form EOS-Moderate Resolution Imaging Spectroradiometer, J. Geophys. Res., 102, 17 051-17 065, 1997.

Kiehl, J. T. and Briegleb, B. P.: The relative roles of sulphate and greenhouse gases in climate forcing, Science, 260, 311-314, 1993.

King, M. D., Kaufman, Y. J., Tanre, D., and Nakajima, T.: Remote sensing of tropospheric aerosols from space: Past, present, and future, Bulletin of the American Meteorological Society, 80, 11, November 1999.

Koelemeijer R. B. A., Stammes P., Hovenier J. W., and De Haan J. D., A fast method for retrieval of cloud parameters using oxygen A-band measurements from the Global Ozone Monitoring Instrument, J. Geophys. Res., 106, 3475-3490, 2001.

Kusmierczyk-Michulec, J., Kruger, O., and Marks, R.: Aerosol influence on the sea-viewing wide-field-of-view sensor bands: Extinction measurements in a marine summer atmosphere over the Baltic Sea, J. Geophys. Res., 104, D12, 14 293-14 307, 1999a.

Kusmierczyk-Michulec, J. and Rozwadowska, A.: Seasonal changes of the aerosol optical thickness for the atmosphere over the Baltic Sea - preliminary results, Oceanologia, 41, 127-145, 1999b.

Kusmierczyk-Michulec, J., de Leeuw, G., and Robles González, C.: Empirical relationship between aerosol mass concentration and Angström parameters, GRL, 29, 10.1029/2001GL014128, 2002. 
Martonchik, J. V. and Diner, D. J.: Retrieval of aerosols and land surface optical properties from multi-angle satellite imagery, IEEE Trans. Geosci. Remote Sens., 30, 223-230, 1992.

Metzger, S. M., Dentener, F. J., Jeuken, A., Krol, M., and Lelieveld, J.: Gas/aerosol partitioning II: Global modelling results, J. Geophys. Res., 10.1029/2001JD001103, 2002.

Mie, G.: Beiträge zur Optik trüber Medien, speziell kolloidaler Metallösungen, Ann. Phys., 25, 377-445, 1908.

Mozurkewich, M.: The dissociation constant of ammonium nitrate and its dependence on temperature, relative humidity and particle size, Atmospheric Environment, 27A, 261-270, 1993.

Nenes, A., Pilinis, C., and Pandis, S. N.: Isorropia: A new thermodynamic model for multiphase multicomponent inorganic aerosols, Aquatic Geochemistry, 4, 123-152, 1998.

North P. R. J.: Estimation of aerosol opacity and land surface bidirectional reflectance from ATSR-2 dual-angle imagery: Operational method and validation, J. Geophys. Res., 107 (D12), 10.1029/2000JD000207, 2002.

Robles González, C., Veefkind, J. P., and de Leeuw, G.: Aerosol optical depth over Europe in August 1997 derived from ATSR-2 data, Geophysical Research Letters, 27, 7, 955-958, 2000.

Schaap, M., Müller, K., and ten Brink, H. M.: Constructing the European aerosol nitrate concentration field from quality analysed data, Atmos. Environ, 36, 8, 1323-1335, 2002a.

Schaap, M., van Loon, M., ten Brink, H. M., Dentener, F. J., and Builtjes, P. J. H.: Nitrate aerosol field over Europe: simulations with an atmospheric chemistry transport model of intermediate complexity, to be submitted to ACP, 2003

Smirnov, A., Yershov, O., and Villevalde, Y.: Measurements of aerosol optical depth in the Atlantic Ocean and Mediterranean Sea, Atmospheric Sensing and Modelling II, Proceedings Europto Series, 2582, 203-214, 1995.

Stammes, K., Tsay, S., Wiscombe, W., and Jayaweera, K.: Numerically stable algorithm for discrete-ordinate-method radiative transfer in multiple scattering and emitting layered media. Appl. Optics 27, 2502-2509, 1988

Tang, I. N.: Thermodynamic and optical properties of mixed-salt aerosols of atmospheric importance, J. Geophys. Res., 102, D2, 1883-1893, 1997.

Tegen, I., Hollrig, P., Chin, M., Fung, I., Jacob, D., and Penner, J.: Contribution of different species to the global aerosol extinction optical thickness: Estimates from model results, J. Geophys.
Res., 102, D20, 23 895-23 915, 1997.

Ten Brink, H. M., Veefkind, J. P., Waijers-Ijpelaan, A., and van der Hage, J. C.: Aerosol light-scattering in The Netherlands, Atmospheric Environment, 30, 24, 4251-4261, 1996.

Ten Brink, H. M., Hensen, A., Khystov, A., van Dorland, R., Jeuken, A., van Velthoven, P., Lelieveld, J., van den Berg, A., Swart, D. P. J., Bergwerff, J. B., and Apituley, A.: Aerosol cycle and influence on the radiation balance. Cluster-project in the National Research Program on Global Air Pollution and Climate Change, npr2, report no. 410200064, 2001.

Veefkind, J. P., van der Hage J. C. H., and ten Brink, H. M.: Nephelometer derived and directly measured aerosol optical depth of the atmospheric boundary layer, Atmos. Res., 41, 217-228, 1996.

Veefkind, J. P. and de Leeuw, G.: A new algorithm to determine the spectral aerosol optical depth from satellite radiometer measurements, J. Aerosol Science, 29, 10, 1237-1248, 1998.

Veefkind, J. P., de Leeuw, G., and Durkee, P. A.: Retrieval of Aerosol Optical Depth over Land using two angle view Satellite Radiometry during TARFOX, Geophysical Research Letters, 25, 3135-3138, 1998.

Veefkind, J. P., de Leeuw, G., Durkee, P. A., Russell, P. B., Hobbs, P. V., and Livingston, J. M.: Aerosol optical depth retrieval using ATSR-2 data and AVHRR data during TARFOX, J. Geophys. Res., 104, D2, 2253-2260, 1999.

Veefkind, J. P., de Leeuw, G., Stammes, P., and Koelemeijer, R. B. A.: Regional Distribution of Aerosol over land derived from ATSR-2 and GOME, Rem. Sens. of the Env., 74, 377-386, 2000.

Wang, M., and Gordon, H. R.: Radiance reflected from the ocean atmosphere system: synthesis from individual components of aerosol size distribution. Appl. Opt., 33, 7088-7095, 1994.

Whitten, G., Hogo, H., and Killus, J.: The Carbon Bond Mechanism for photochemical smog, Env. Sci. Techn. 14, 14690-14 700, 1980.

Zhang, Y., Seigneur, C., Seinfeld, J. H., Jacobson, M., Clegg S. L., and Binkowski, F. S.: A comparative review of inorganic aerosol thermodynamic equilibrium modules: differences, and their likely causes, Atmospheric Environment, 34, 117, 2000.

Zimmerling, R., Dommgen, U., and Behrens, U.: Konzentrationen versauernd und eutrophierend wirkender Spurengase und Aerosol-Bestandteile in Nordost-Brandenburg, Landbauforschung Volkenrode, special issue 213, 43-93, 2000. 